\title{
Empowering Women in the Chinese Capitalist Factory System
}

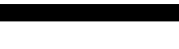

Sara Akl

Bachelor of Arts, Foreign Affairs and Biology University of Virginia, 2013

Over the past thirty years, China has moved from a communist to a capitalist economy. This change has pushed millions of young, rural women to migrate to the cities in order to begin working in its many booming factories. These women, if they manage to avoid falling prey to false advertising and trafficking scams, enter the competitive capitalist system at the absolute lowest level. They find employment in foreign-invested companies, usually producing toys, clothing, footwear, and electronics. ${ }^{1}$ Their service positions in an unregulated labor market subordinate them, and factory women are constantly reminded of their low positions within the workplace.

Although

economists and supporters of the free market assert that the transition from rural farming to urban factory work empowers women, in practice it merely places women at the bottom of a corrupt, unregulated system. ${ }^{2}$ Instead of taking this same approach, in this paper I will search for integrationist strategies that answer specific questions. How can migrant women become empowered within the

capitalist system, we must first understand how women entered into this arrangement of miserable jobs, and why they do so. There are certain incentives for rural women, especially unmarried ones, to urbanize, including the desire for independence and a better life, the obligation of honoring family, or the necessity of money. In addition, young migrants supporting their families often enjoy an elevated social status - these hierarchy of China's capitalist factory system? How have measures taken by the state, NGOs, and factory-employed women themselves affected women's ability to gain status within the workplace? China's state policies enable, and sometimes force, women into the bottom of the capitalist system without effective enforcement of potential helpful ordinances. However NGOs, such as the Asia Foundation, the HERproject, and the Chinese Working Women Network, provide programs and workshops in education, training, health services, and legal aid, in addition to support networks within and outside of the factory. Female workers within the factories also serve to empower themselves directly by confronting their bosses and even going on strike, despite the risks associated with speaking out.

To understand how women can



Chinese women in Nanjing carrying
vegetables and fruits across town.

women have more bargaining power in their hometowns and can negotiate on certain issues, such as finding a male partner or a permanent residence in the city. ${ }^{3}$ Women are encouraged to leave the home to work the assembly lines of Dongguan (one of the largest factory cities in China) are estimated at seventy percent female. ${ }^{4}$ This is because families view their daughters as disposable empower themselves in the current Chinese labor; because they matter less, they are free to leave and begin new lives in the cities. These "new lives" are often very difficult. As author Leslie Chang points out, "The city does not offer them easy living. The pay for hard labor is low - often lower than the official minimum wage...Get hurt, sick, or pregnant, and you're on your own. ${ }^{5}$ Chinese women, after "empowering themselves", begin at the bottom of the capitalist pool. This situation is far from ideal, and we must endeavor to procure different options for women to become truly empowered in the workforce.

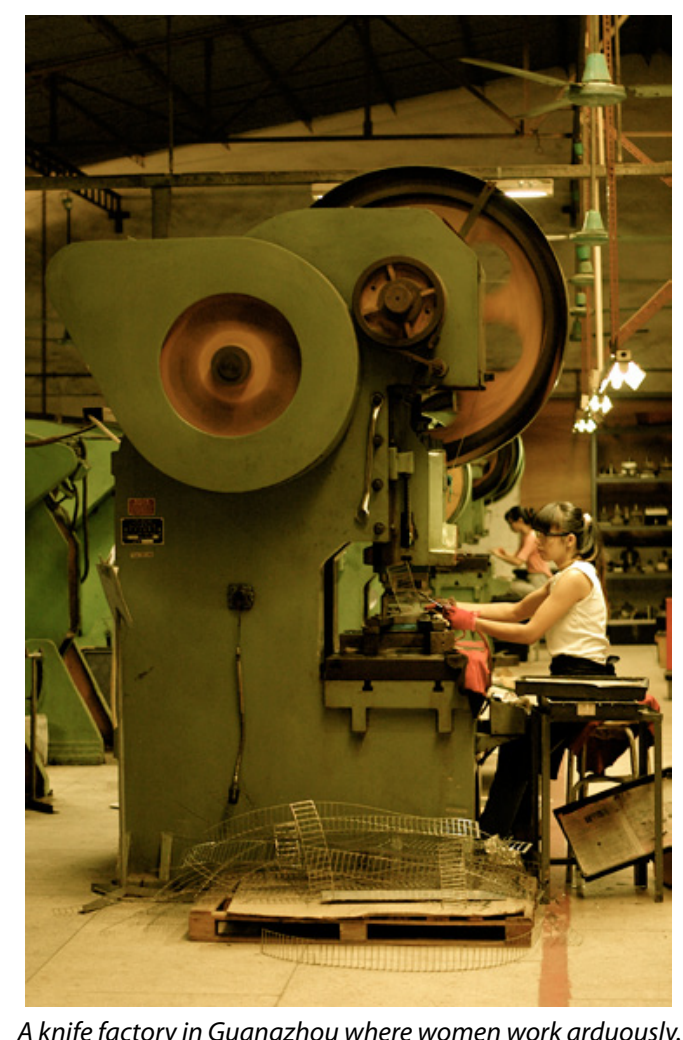

After the fall of communism and the opening of China's labor markets, the policies enacted by the state created an apartheid-esque social structure that placed the migrant workers in a no-man's land the more educated workers disdain the men from the rural villages, but city men, in turn, look down on migrant women ${ }^{6}$ These problems with class struggle have gone unresolved by the federal government.
Women specifically have found government practices and propaganda to be detrimental to their careers, as China "fosters the idea of marriage and/or pregnancy as the 'natural' termination of factory employment". These young women are not interested in relinquishing their freedom by quitting the factories to work for their husbands, but the state continues to enforce the traditional marriage system within the rural communities. China has enacted several labor laws designed to protect workers, but the arm of the government never seems to reach into the provinces. Because residential laws remain unchanged, the federal government controls nearly nothing in the day-to-day of the young factory workers. ${ }^{8}$ State policy has not evolved enough to give women the opportunities they need and desire to succeed within the capitalist system, but women do succeed despite this. This is because they still have two possible sources to utilize. Migrant women, in lieu of help from the state, make use of NGOs as well as their own negotiating power.

As China has relinquished its hold on all organizations working within the state, NGOs have appeared and begun attempting to aid the millions of female migrant workers. These NGOs include the Asia Foundation, the HERproject, and the Chinese Working Women Network. Each of these projects has different goals, but all aim to empower women with knowledge and support, helping them to better their lives in multiple aspects. They accomplish this objective by working with different factories across multiple industries.

Over the past ten years, the Asia Foundation has created programs in China to empower women economically. In 1999, Asia Foundation developed activities including counseling, training, and legal aid services for workers, all free of charge, using local organizations in the Guangdong province, in which sixty percent of migrant labor is female. ${ }^{9}$ This NGO realized the limits 
of the government's household registration system and worked around it, providing migrant women with services they sometimes desperately required. These services are often the only support that migrant workers can hope to receive upon moving to a new city with an immediate second-class citizenship. NGO legal services can help improve the capacity of labor bureaus, train labor inspectors, and provide good legal aid for workers - thus being is a safety net that can empower migrant women to take a stand against unfair treatment within a factory.

Education remains one of the most important facets of Asia Foundation's work. In 2005, the NGO created the Scholarship Program for Migrant Women Works, and

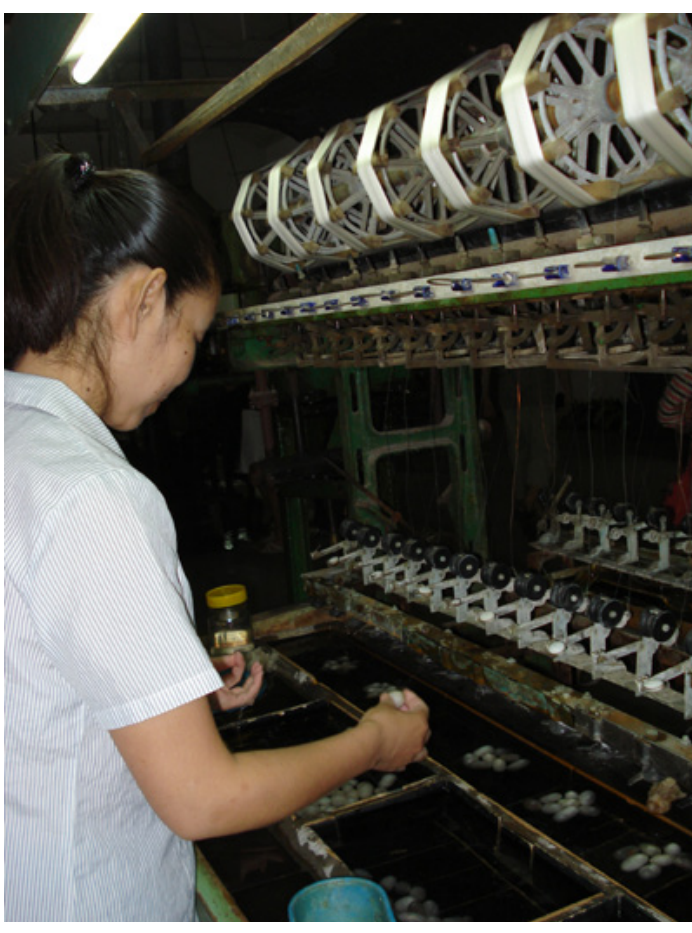

A Chinese woman workign in a factory in Suzhou.

committed itself to helping women advance their careers through a vocational school and a university scholarship program. Asia Foundation remained conscious of women who studied part-time in order to balance education with their work schedules. ${ }^{10}$ Also in 2005, the Asia Foundation, through a partnership with Microsoft, developed the Increasing IT Literacy program. The grant from Microsoft helped establish Communications Technology Learning Centers, which taught basic computer skills to migrant women workers in addition to disadvantaged local community members. ${ }^{11}$ In a market system where potential employers looks at applicable skills first, these projects are immensely helpful in allowing women the opportunity to move forward.

The Asia Foundation, in a desire to bring together industry and NGO, sponsored a workshop in 2003 called the Workshop on Direct Labor Service Programs. Over thirty multinational corporations, trading companies, and international NGOs met with Chinese NGOs and academics in order to improve Chinese working conditions. Although few tangible results followed, participants agreed on establishing an annual roundtable discussing specific topics, such as health, education, and safety. These discussions would involve workers, government officials, NGOs, and corporations. ${ }^{12}$ Health issues are very important, and Asia Foundation has worked hard distributing information and conducting classes on disease prevention, AIDS/HIV awareness, female hygiene, and occupational diseases.

Because of the prevalence of health issues, other organizations, such as HERproject, have appeared to supplement the work of other NGOs. HERproject is a BSR initiative, which promotes corporate responsibility, and it utilizes companies, NGOs, and foundations to improve the lives of female workers. In China, HERproject has cited seven major health issues: breast and cervical cancer, exposure to chemical hazards, feminine hygiene and STDs, HIV/ AIDS, malnutrition, depression, and painful menstruation. ${ }^{13}$ Much of the risk presented by the HERproject acknowledges ignorance as a main issue; many women do not receive sufficient training when handling hazardous chemicals and choose not to wear protective gear. Women are unaware of their risk for STDs or HIV/AIDS, often because factory management wrongly assumes unmarried women are not having sex. Because health care facilities in factories cannot write prescriptions and few migrant women have health insurance, drastic measures are often taken. ${ }^{14}$ Chang noticed a man, "a chain-smoker with a hacking cough [who] did not look in the least qualified

\section{These interpersonal skills give women the ability to move upwards in their jobs as well as remain healthy.}

to be giving out medical opinions. Yet a crowd of young men and women clamored for the flyers he was handing out," which demonstrates the necessity of other options..$^{15}$ In 2009, HERproject received aid from Marie Stopes International to support a health program in the Guangdong, Jiangsu, and Zhejiang provinces. The results are inspiring. Improved knowledge about all health issues made workers both healthier and happier at work and gave them greater confidence to discuss health issues. ${ }^{16}$ These interpersonal skills give women the ability to move upwards in their jobs as well as remain healthy, a definite benefit.

Aside from the educational, legal, and health programs administered by Asia Foundation and HERproject, the Chinese Working Women Network provides migran women with something they miss while away from their homes: a social network. The Cultural Women Workers Centre offers "a cultural and physical space to building up collectivity apart from [the] factory shop floor and dormitory."17 Using social interaction, including reading groups, singing groups, poetry groups, the Centre simultaneously allows women to form support networks and educates them on labor law, feminist rights, and occupational health. In addition, CWWN owns a bus that caters to migrant women in Shenzhen and the Pearl River Delta economic zone. ${ }^{18}$ This is a great aid to migrant workers, who have no other means of transport, especially if they are hunting for better job upgrades across cities. In 2000, the Chinese Working Women Network began factory training for production workers. They built a model of education for workers' empowerment with a curriculum focusing on labor rights, corporate responsibility, safety, health, and

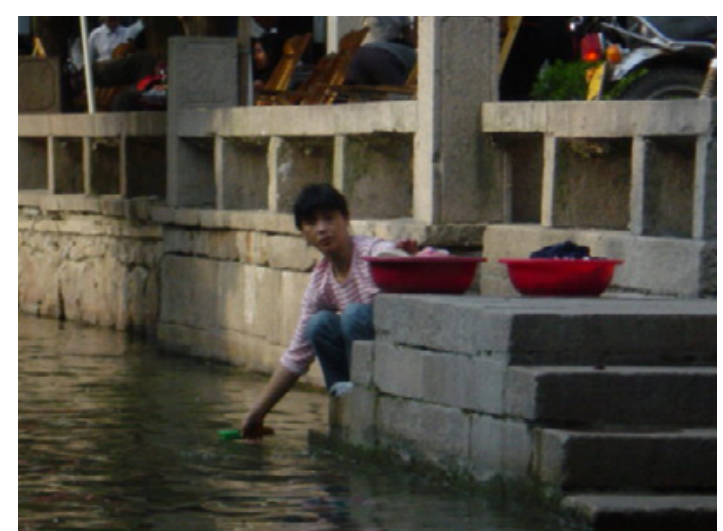

A woman washing clothes in a canal, Zhouzhang Jiangsu.

communication. ${ }^{19}$ Hopefully, this program will enhance the decision-making skills of assembly-line workers, enabling them to rise within the capitalist market system.

The NGOs working in China today can help to empower these somewhat educated, young, rural migrant women by furthereducating them. Knowledge is power and security. NGOs like Asia Foundation, projects like HERproject, and networks like CWWN give women the opportunity to learn and to become empowered in China's factories. Of course, these are nascent initiatives, and it is uncertain whether they will ultimately make enough of a difference.

NGO programs are beneficial, but they are sometimes not enough or not present at all in some provinces. In this case, multiple studies have affirmed one thing - in order for a migrant woman to get ahead in the cutthroat capitalist world, 
she must rely on herself. There are several better job prospects. ${ }^{22}$ Chang recounted opportunities for women to empower tales of women hopping cities each month in order to make some extra Yuen or of women standing up to a boss, quitting in relocate to a safer factory, hoping to make favor of a different job, and actively seeking enough money to quit the system or rise out "good" factories. Chang found that, within it, "A young woman went to the city, "The turning point in a migrant's fortunes endured hardship, and triumphed, usually always came when she challenged her by starting her own business...you can only boss. At the moment she risked everything, rely on yourself."23 Despite claims by older she emerged from the crowd and forced studies that job mobility is low in China, the world to see her as an individual," and Chang found that almost all the senior one of her subjects, Chunming, used this people in factories began on the assembly strategy multiple times in order to receive line. ${ }^{24}$ The most assured way to create good raises, promotions, and equal treatment. ${ }^{20}$ opportunities was to find a good factory After jumping factories, she had discovered from the beginning; less time factory that her department heads received higher hopping and working in a "benign factory salaries, though they performed the same context" was conducive to open discussion tasks. She fought back, writing to them, "If and empowerment. ${ }^{25}$ By searching right you don't increase my salary to 1,500 Yuan a month...I refuse to do this anymore," and she got what she wanted. ${ }^{21}$ She was boldly friendly with her managers, studying the higher-ups in order to become an expert in public relations. Although she found herself at the bottom of the barrel in the beginning, her own initiative and bravery led her to move upwards very quickly. This internal strength is something all working migrant women possess, and it should be utilized more often. Each woman's personal struggle against oppressive forces reaches a zenith when she realizes that she is her own greatest weapon against those forces. However, there are obvious risks associated with standing up and demanding rights - some factories do not allow their women to demand equality or empowerment. Bosses could easily firer low factory workers, and they oftentimes secretly attempt to replace the higher-level female workers who challenged them. In those instances, Chang and researchers Lang Ma and Francine Jacobs found that women merely "voted with their feet," meaning that they quit. They used the ever-flowing market to their advantage and many girls used this strategy to obtain power, NGOs provide helpful programs that function where the federal government fails, providing education for young girls regarding health issues, legal aid, and scholarly pursuit. These NGO programs can have vast impacts on the psyche of workers, enabling them to discuss new subjects with coworkers and bosses. Furthermore, NGOs offer services, such as transportation

\section{Endnotes}

Zhang Ye, "Migrant Women Negotiate Foreign Investment in Southern Chinese Factories." Signs. (The University of Chicago Press, 2004) 540-543.

2 Teri L. Caraway, "Feminized Ghettos? The Structural Contours of Women's Employment." Assembling Women: The Feminization of Global Manufacturing. (lthaca: Cornell University Press, 2007) 36-61.

3 Eileen M. Otis, "Reinstating the Family: Gender and the State-Formed Foundations of China's Flexible Labor Force." Haney, Lynne and Lisa Pollard. Families of a New World: Gender, Politics, and State Development. (New York: Routledge, 2003) 196216.4

4 Chang, Leslie T. Factory Girls: From Village to City in a Changing China. (Random House, 2008) 25.

5 Chang 11 .

7 Mary Gallagher, "Review." The China Journal. Australian National University, (2001) 163-165.

8 Chang 32 .

9 China CSR Map. Asia Foundation. <http://www.chinacsrmap.org/E_OrgShow.asp?CCMOrg_ID=950>.

10 China CSR Map.

12 The Asia Foundation. Programs to Support Migrant Women Workers. 2, 2004. <http://www.plenet.org.uk/data/files/asiafoundation-programme-to-support-migrant-women-workers-2004-310.pdf>

13 HERproject. Female Factory Workers' Health Needs Assessment: China. 7, 2010. <http://herproject.org/downloads/countryresources/her_health_needs_china.pdf $>$.

14 HERproject

5 Chang, Leslie T. Factory Girls: From Village to City in a Changing China. (Random House, 2008) 111

6 HERproject

7 The Chinese Working Women Network. <http://www.cwwn.org/eng/eng_main.html>.

18The Chinese Working Women Network

20 Chang 55.

22 Lang Ma and Francine Jacobs. Poor but not Powerless. Women Workers in Production Chain Factories in China (SAGE 2010) 13.

23 Chang 62

24 Chang 27.

25 Ma and Jacobs 10

Photos courtesy of:

http://commons.wikimedia.org/wiki/File:Chinese_knife_factory.jpg

http://commons.wikimedia.org/wiki/File:Chiny_Shuzhou_tkalnia_jedwabiu_09.JPG

g_basket.jpg

http://commons.wikimedia.org/wiki/File:Women_washing_clothes_in_a_canal,_Zhouzhuang_Jiangsu_China.jpg 